\title{
An assessment of cerebral venous thrombosis risk factors and associated clinical outcomes in Jazan region, Saudi Arabia
}

Hasan M. Daghriri, MBBS, Alwaleed A. Alrajhi, MBBS, Khadijah S. Aburasain, MBBS, Ebtisam A. Ateya, MBBS, Mohammed A. Hakami, MD, Ibrahim M. Gosadi, MPH, PhD.

\begin{abstract}
الأهداف : دراسة عوامل خطورة التخثر الوريدي الدماغي و النتائج

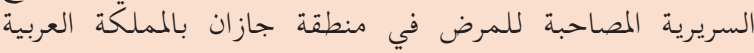
السعودية.

المنهجية: أجريت هذه الدراسة الاستعادية للسجلات الطبية

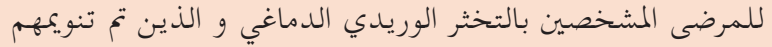

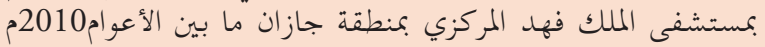

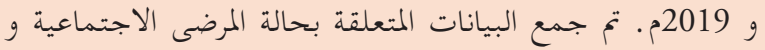

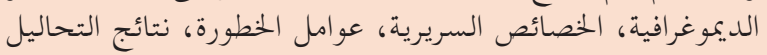

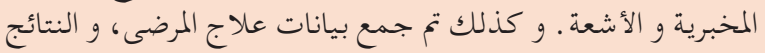

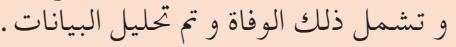

النتائج: تم التعرف على 51 سجلاً طبياً. أغلبية المرضى كانوا

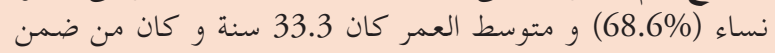

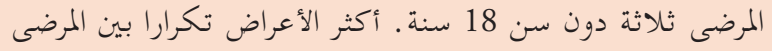

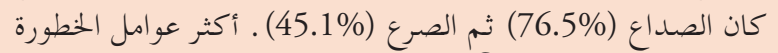

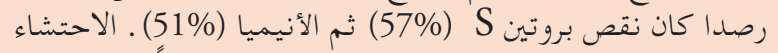

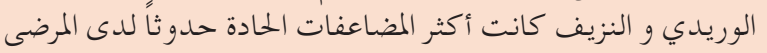

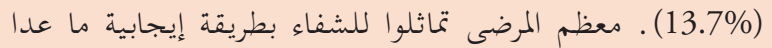

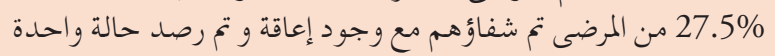

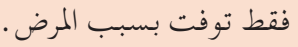

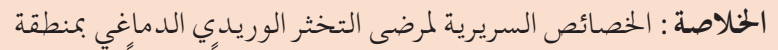

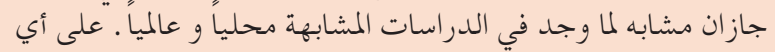

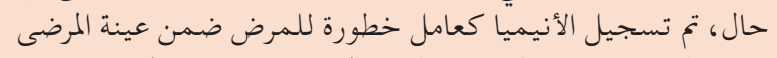

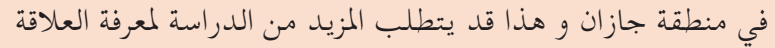

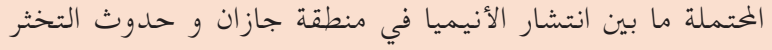

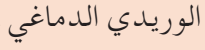

Objectives: To assess cerebral venous thrombosis risk factors, and associated clinical outcomes in Jazan region, Kingdom of Saudi Arabia.

Methods: This study is a retrospective review of the medical records of patients diagnosed with cerebral venous thrombosis and admitted to King
Fahad Central Hospital in Jazan between 2010 and 2019. Data concerning socio-demographics, clinical features, risk factors, laboratory, and imaging investigations were retrieved. Furthermore, data about cases management, and outcomes, including death, were collected and analysed.

Results: A total of 51 medical records were identified. The majority of the patients were females (68.6\%), and the mean age of the patients was 33.3 years, of which three patients were under 18 years old. The most frequently recorded symptom was headache (76.5\%), followed by seizure $(45.1 \%)$. The most commonly recorded risk factor was protein $\mathrm{S}$ deficiency (57\%), followed by anaemia (51\%). Venous infarction and haemorrhage were the most common acute complications (13.7\%). The majority of the patients had a favourable prognosis where only $27.5 \%$ recovered with disability and only one patient died due to the disease.

Conclusion: Clinical presentation of cerebral venous thrombosis in Jazan region is similar to other local and international studies. However, anaemia was recorded as a main risk factor for the disease, which might require further investigation to assess the possible association between prevalence of anaemia in Jazan region and the incidence of cerebral venous thrombosis.

Neurosciences 2021; Vol. 26 (1): 15-20 doi: 10.17712/nsj.2021.1.20200098

From the Faculty of Medicine (Daghriri, Alrajhai, Aburasain, Ateya), Department of Family and Community Medicine (Gosadi), Faculty of Medicine, Jazan University, and Department of Neurology (Hakami), King Fahad Central Hospital, Jazan, Kingdom of Saudi Arabia.

Received 11th June 2020. Accepted 2nd September 2020.

Address correspondence and reprint request to: Ibrahim M. Gosadi, Faculty of Medicine, Jazan University, Jazan, Kingdom of Saudi Arabia.E-mail:gossady@hotmail.com

ORCID ID: https://orcid.org/0000-0002-1275-3953 
$\mathrm{C}$ erebral venous thrombosis (CVT) is a rare form of cerebrovascular disease in comparison with arterial stroke. CVT cases represent approximately $0.5-1 \%$ of all types of stroke which mainly occur in young and middle-aged adults. ${ }^{1}$ The data concerning the global epidemiology of CVT is currently limited. ${ }^{2}$ However, the incidence of CVT has been reported to vary between countries where the incidence might be higher as in Asian and the Middle Eastern countries in comparison to Australia and European countries. ${ }^{3}$

According to a recent study conducted in Australia, the incidence of CVT was reported to reach 15.7 per $1,000,000$ persons on a yearly basis. The incidence was higher among women and among those between 31-50 years old. ${ }^{4}$ In the Middle East, an Iranian study looked at the frequency of CVT between 2001 and 2004, and the annual frequency of CVT was 12.3 per one million. ${ }^{5}$ An older study, conducted in the city of Riyadh in Saudi Arabia between 1985 and 1994, identified 40 cases of CVT. Those identified were aged between 16 and $40 .^{6}$ In addition, in a more recent study conducted in Jeddah and Al-Baha between 1990 and 2010, the number of detected cases of CVT was 111 where 19 of these were detected among children.?

The CVT occurs when a thrombus develops as a result of a disturbance of the balance between the process of prothrombosis and thrombolysis. ${ }^{8,9}$ Risk factors for CVT can be categorised into transient and permanent risk factors. Permanent risk factors are hereditary thrombophilia, systemic diseases or miscellaneous factors, such as obesity. Transient risk factors can be subcategorised into sex-specific, iatrogenic, or miscellaneous risk factors, such as infection, head trauma or anaemia. ${ }^{8}$ The prevalence of CVT risk factors differs between countries. Infection, pregnancy, post-partum period, and dehydration have been reported to be more common in Asia and the Middle Eastern countries in comparison to European countries. ${ }^{8}$

Patients with CVT exhibit variable clinical manifestations and complications, some of which can be life threatening. The most common clinical presentation is a headache, while some patients exhibit other signs and symptoms, such as seizure, decreased level of consciousness, vomiting, focal neurological deficit, or visual symptoms. ${ }^{8-10}$ Venous infarction and haemorrhage are frequently reported complications of CVT. ${ }^{11}$ Late presentation of CVT patients can increase

Disclosure. Authors have no conflict of interests, and the work was not supported or funded by any drug company. the risk of disability and death. The mortality rate among CVT patients has been reported to vary between $4.3 \%$ and $6.8 \% .^{12}$

Since CVT risk factors and vulnerable groups can vary between different populations, assessment of the distribution of risk factors among local populations can be clinically valuable. Studies assessing CVT prevalence and associated risk factors and clinical outcomes in Saudi populations are currently limited. Furthermore, data about CVT in Jazan region is currently lacking. This investigation aims to identify cases diagnosed with CVT in Jazan region and to evaluate the risk factors and associated clinical outcomes.

Methods. This study is a retrospective review of the medical records of patients diagnosed with CVT and admitted to King Fahad Central Hospital (KFCH) in Jazan region. Jazan is located in the south west of Saudi Arabia, on the northern border with Yemen. $\mathrm{KFCH}$ is a referral tertiary hospital designated for the management of CVT patients. Ethical approval to conduct the study was granted by Jazan Hospital IRB (approval number 1933) and the study was conducted in accordance with the principles of Helsinki Declaration. Medical literature was searched utilizing cerebral, venous, thrombosis, Jazan, and Saudi Arabia as key terms to find relevant local or international studies from multiple databases including Pubmed, Google Scholar, Research Gate, and screening reference lists of identified relevant articles.

The hospital's electronic medical records system was accessed to retrieve patients' data. The electronic medical records system was established at $\mathrm{KFCH}$ in 2010. Therefore, cases recorded as CVT cases were targeted over a period between 2010 and 2019. The electronic medical records system enabled searching via terminologies pertaining to the submitted diagnosis, such as cerebral venous thrombosis and CVT. The inclusion of CVT cases was based on the availability of initial diagnosis of CVT confirmed via radiological imaging, such as a Computed Tomography (CT) scan, CT Venogram, Magnetic Resonance Imaging (MRI), and Magnetic Resonance Venography (MRV). Cases were excluded if they were not confirmed by radiological imaging modalities, if they were incomplete, or if they were a duplicated record.

Data extraction sheet was developed to record the study's variables. The retrieved socio-demographics variables included age, gender, and Body Max Index (BMI). The retrieved clinical features at the time of admission were related to headache, vomiting, seizure, visual disturbance, weakness or numbness, altered sensorium, speech difficulty, decreased level of consciousness, cranial nerve palsy, papilledema, and duration of the these symptoms. Retrieved risk 
Table 1 - Demographic characteristics of 51 patients diagnosed with CVT in King Fahad Central Hospital, in Jazan region between 2010 and 2019.

\begin{tabular}{lccc}
\hline Demographic characteristics & Gender - Frequency $(\%)$ & Total \\
Male & $16(31.4)$ & & $51(100)$ \\
Female & $35(68.6)$ & & \\
\hline Age & & & \\
Mean \pm SD & $31.25 \pm 14.55$ & $34.29 \pm 9.69$ & $33.33 \pm 11.38$ \\
Minimum & 5 & 18 & 5 \\
Maximum & 55 & 57 & 57 \\
Nationality & & & \\
Saudi & $11(68.8)$ & $28(80)$ & $39(76.5)$ \\
Non-Saudi & $5(32.3)$ & $7(20)$ & $12(23.5)$ \\
Chronic disease & & & \\
Hypertension & $1(6.3)$ & $3(8.6)$ & $4(7.8)$ \\
Diabetes & $0(0)$ & $2(5.7)$ & $2(3.9)$ \\
Asthma & $1(6.3)$ & $2(5.7)$ & $3(5.9)$ \\
BMI & & & \\
Normal & $4(25)$ & $12(34.3)$ & $16(31.4)$ \\
Underweight & $2(12.5)$ & $0(0)$ & $2(3.9)$ \\
Overweight & $9(56.3)$ & $9(25.7)$ & $18(35.3)$ \\
Obese & $1(6.3)$ & $13(37.1)$ & $14(27.5)$ \\
Previous history of CVT & $1(6.3)$ & $3(8.6)$ & $4(7.8)$ \\
Family history of CVT & $0(0)$ & $0(0)$ & $0(0)$ \\
\hline & & &
\end{tabular}

factors for CVT, and laboratory investigation included Complete Blood Count (CBC), Hypercoagulopathy workup (Protein C, Protein S, Homocysteine, Factor V Leiden mutation), Auto-immune tests (Anti-thrombin III Anti-cardiolipin antibody, Lupus anticoagulant, Anti-double stranded DNA antibody). The retrieved imaging details were related to the used modality, name and number of involved sinuses, and type of parenchymal lesion. Furthermore, data about cases management and outcomes including acute and chronic complications in addition to death were retrieved.

Data analysis was performed via the statistical package for the social sciences (SPSS) (version 25). Frequencies and proportions were used to summarise binary and categorical study variables. Mean and Standard Deviations (SD) were utilised to summarise continuous variables.

Results. A total of 380 medical records of CVT cases were identified via the electronic medical records system. After reviewing the identification data of the selected records, 228 records were found to be duplicates and were excluded. Furthermore, after excluding records that had no confirmatory imaging or were incomplete, only 51 medical records were eligible to be included in the current investigation.

The demographic data of the included patients is described in Table 1. Among the included patients, 35
Table 2 - Clinical features, complications and prognosis of 51 patients diagnosed with CVT in King Fahad Central Hospital, in Jazan region between 2010 and 2019.

\begin{tabular}{|c|c|c|}
\hline Variables & $\mathrm{n}$ & $(\%)$ \\
\hline \multicolumn{3}{|l|}{ Signs and symptoms } \\
\hline Headache & 39 & $(76.5)$ \\
\hline Seizure & 23 & $(45.1)$ \\
\hline Vomiting & 17 & $(33.3)$ \\
\hline Visual symptom & 9 & $(17.6)$ \\
\hline Weakness & 10 & $(19.6)$ \\
\hline Numbness & 2 & $(3.9)$ \\
\hline Altered sensorium & 1 & $(2.0)$ \\
\hline Speech difficulty & 4 & $(7.8)$ \\
\hline Decreased level of consciousness & 7 & $(13.7)$ \\
\hline Coma & 2 & $(3.9)$ \\
\hline Cranial nerve palsy & 3 & $(5.9)$ \\
\hline Papilledema & 7 & $(13.7)$ \\
\hline \multicolumn{3}{|l|}{${ }^{*}$ Mode of onset } \\
\hline Acute & 2 & $(3.9)$ \\
\hline Subacute & 23 & $(45.1)$ \\
\hline Chronic & 5 & $(9.8)$ \\
\hline \multicolumn{3}{|l|}{ Findings on clinical examination } \\
\hline Upper limb weakness & 9 & $(17.6)$ \\
\hline Lower limb weakness & 6 & $(11.8)$ \\
\hline Upper limb numbness/loss of sensation & 3 & $(5.9)$ \\
\hline Lower limb numbness/loss of sensation & 4 & $(7.8)$ \\
\hline Cranial nerve palsy & 2 & $(3.9)$ \\
\hline Normal & 37 & $(72.5)$ \\
\hline $\begin{array}{l}\text { Duration of symptoms and signs } \\
\text { (Days): }\end{array}$ & $\begin{array}{c}25.63 \pm 53.53 \\
\text { Mean } \pm S D\end{array}$ & Median $=5$ \\
\hline \multicolumn{3}{|l|}{ Acute complications } \\
\hline Venous infarction $\&$ hemorrhage & 7 & $(13.7)$ \\
\hline Coma & 2 & $(3.9)$ \\
\hline Subarachnoid hemorrhage & 1 & $(2)$ \\
\hline Ophthalmoplagia & 1 & (2) \\
\hline No acute complications & 39 & $(76.5)$ \\
\hline \multicolumn{3}{|l|}{ Chronic complications } \\
\hline Epilepsy & 13 & $(25.5)$ \\
\hline Focal neurological deficit & 8 & $(15.7)$ \\
\hline No chronic complications & 35 & $(68.6)$ \\
\hline \multicolumn{3}{|l|}{ Prognosis } \\
\hline Complete recovery & 34 & $(66.7)$ \\
\hline $\begin{array}{l}\text { Recovery with disability } \\
\text { Death }\end{array}$ & $\begin{array}{c}14 \\
1\end{array}$ & $\begin{array}{c}(27.5) \\
(2)\end{array}$ \\
\hline
\end{tabular}

patients (68.6\%) were females, and the mean age of the CVT patients was 33.3 years, of which three patients were under 18 years old. The majority of the patients were Saudis and were either overweight. The most frequently recorded chronic disease was hypertension and only 4 patients had previous history of CVT. None of the patients had a family history of CVT. 
The clinical features, complications and prognosis of the included patients are described in Table 2. The most frequently recorded symptom was headache $(n=39,76.5 \%)$, followed by seizure $(n=23,45.1 \%)$. The majority of patients had subacute onset of the symptoms. The findings of the neurological examination indicate that the majority of patients had no limb weaknesses,

Table 3 - Recorded CVT risk factors of 51 patients diagnosed with CVT in King Fahad Central Hospital, in Jazan region between 2010 and 2019:

\begin{tabular}{lcc}
\hline Risk factors & $\mathbf{n}$ & $(\%)$ \\
\hline Infection of head and neck & 1 & $(2)$ \\
Head trauma & 1 & $(2)$ \\
Anemia & 26 & $(50.98)$ \\
Dehydration & 1 & $(2)$ \\
Obesity & 14 & $(27.5)$ \\
Hypercoagulapathy status: & & \\
Hereditary thrombophilia & 2 & $(3.9)$ \\
Protein C deficiency & 8 & $(15.7)$ \\
Protein S deficiency & 29 & $(56.9)$ \\
Anti-thrombin III deficiency & 7 & $(13.7)$ \\
Factor V Leiden mutation & 1 & $(2)$ \\
Anti-phospholipid syndrome & 11 & $(21.7)$ \\
Systemic diseases: & & \\
Inflammatory bowel disease & 1 & $(2)$ \\
Thyroid disease & 2 & $(3.9)$ \\
Systematic Lupus Erythematosus (SLE) & 1 & $(2)$ \\
Female-specific risk factors: & & \\
Pregnancy & 2 & $(3.9)$ \\
Puerperium & 15 & $(29.4)$ \\
Oral contraceptive pills (OCP) & 8 & $(15.7)$ \\
Hormonal Replacement Therapy (HRT) & 1 & $(2)$ \\
Unknown risk factors & 8 & $(15.7)$ \\
\hline
\end{tabular}

CVT - Cerebral Venous Thrombosis numbness, loss of sensation, or palsy ( $\mathrm{n}=37,72.5 \%)$. However, 15 patients suffered from either upper or lower limb weaknesses. Finally, the mean duration of the symptoms and signs was 25 days.

Venous infarction and haemorrhage were the most common acute complications among the included CVT patients $(n=7,13.7 \%)$, followed by coma $(n=2$,

Table 4 - Radiological features of 51 patients diagnosed with CVT in King Fahad Central Hospital, in Jazan region between 2010 and 2019 .

\begin{tabular}{lcc}
\hline Radiological features & $\mathbf{n}$ & $(\%)$ \\
\hline Used modalities & & \\
CT scan & 31 & 60.8 \\
MRI & 21 & 56.9 \\
CT venogram & 25 & 49 \\
MR venogram & 5 & 9.8 \\
Parenchymal lesion & & \\
Hemorrhagic lesion & 15 & 29.4 \\
Non-hemorrhagic lesion & 24 & 47.1 \\
Subarachnoid hemorrhage & 2 & 3.9 \\
No parenchymal lesion & 10 & 19.6 \\
Involved sinuses/veins & & \\
Superior sagittal sinus & 33 & 64.7 \\
Inferior sagittal sinus & 4 & 7.8 \\
Transverse sinus & 39 & 76.5 \\
Sigmoid sinus & 27 & 52.9 \\
Straight sinus & 10 & 19.6 \\
Deep cerebral vein & 1 & 2 \\
Internal jugular vein & 18 & 35.3 \\
Cortical vein & 2 & 3.9 \\
Number of involved sinuses/veins & & \\
One & 14 & 27.5 \\
Two & 7 & 13.7 \\
More than 2 & 29 & 56.9 \\
\hline
\end{tabular}

Table 5 - Comparison between different studies conducted in Saudi Arabia to investigate clinical features of CVT.

\begin{tabular}{|c|c|c|c|c|}
\hline $\begin{array}{l}\text { City: period of records review } \\
\text { [Reference] }\end{array}$ & $\begin{array}{l}\text { Jazan: } 2010-2019 \\
\text { Current study }\end{array}$ & Khobar: 2008-2018 ${ }^{13}$ & $\begin{array}{c}\text { Jeddah \& Al-Baha } \\
1990-2010^{7}\end{array}$ & Riyadh: $2005-2008^{14}$ \\
\hline Number of patients & 51 & 26 & 111 & 22 \\
\hline Mean age of patients & 33.33 & 29.4 & 29.5 & 38.3 \\
\hline $\begin{array}{l}\text { Most common clinical } \\
\text { presentation }\end{array}$ & $\begin{array}{l}\text { 1-Headache } \\
\text { 2-Seizure } \\
\text { 3-Vomiting }\end{array}$ & $\begin{array}{l}\text { 1-Headache } \\
\text { 2-Unilateral weakness } \\
\text { 3-CN palsy }\end{array}$ & $\begin{array}{c}\text { 1-Headache } \\
\text { 2-Focal neurological deficit } \\
\text { 3-Seizure }\end{array}$ & $\begin{array}{c}\text { 1-Headache } \\
\text { 2-Seizure } \\
\text { 3-Focal neurological deficit }\end{array}$ \\
\hline Most common risk factors & $\begin{array}{l}\text { 1-Protein } S \text { deficiency } \\
\text { 2-Anemia } \\
\text { 3-Puerperium }\end{array}$ & $\begin{array}{c}\text { 1-OCP/postpartum } \\
\text { 2-Infection } \\
\text { 3-Trauma and hereditary } \\
\text { thrombophilia }\end{array}$ & $\begin{array}{l}\text { 1-Pregnancy / puerperium } \\
\text { 2- antiphospholipid antibody } \\
\text { syndrome } \\
\text { 3-OCP }\end{array}$ & $\begin{array}{c}\text { 1-OCP } \\
\text { 2-Protein S deficiency } \\
\text { 3-Unkown }\end{array}$ \\
\hline Most common involved sinuses & $\begin{array}{l}\text { 1-Transverse sinus } \\
\text { 2-Superior sagittal sinus } \\
\text { 3-Sigmoid sinus }\end{array}$ & $\begin{array}{c}\text { 1-Transverse sinus } \\
\text { 2-Superior sagittal sinus } \\
\text { 3-Sigmoid sinus }\end{array}$ & Superior sagittal sinus & $\begin{array}{c}\text { 1-Transverse sinus } \\
\text { 2-Sigmoid sinus } \\
\text { 3-Superior sagittal sinus }\end{array}$ \\
\hline $\begin{array}{l}\text { Most common type of } \\
\text { parenchymal lesion on imaging }\end{array}$ & Non-hemorrhagic lesion & Hemorrhagic lesion & Not mentioned & Hemorrhagic lesion \\
\hline
\end{tabular}


$3.9 \%)$. However, the majority of the patients did not experience any acute complications ( $\mathrm{n}=39,76.5 \%)$. Regarding chronic complications, epilepsy was the most common complication, affecting 13 patients (25.5\%), while eight patients (15.7\%) experienced focal neurological deficit. Nevertheless, the majority of the patients $(n=35,68.6 \%)$ did not develop any chronic complications. The majority of the patients had a favourable prognosis, with 34 patients $(66.7 \%)$ having a complete recovery. Only 14 patients $(27.5 \%)$ recovered with disability and only one patient was recorded to have died due to CVT.

The recorded risk factors of CVT are described in Table 3. The most commonly recorded risk factor was protein $S$ deficiency $(n=29,57 \%)$, followed by anaemia $(n=26,51 \%)$. Although protein $S$ deficiency can be manifested during the acute phase of thrombosis, the average duration between incidence of CVT and time of protein $S$ measurement among patients identified with protein $S$ deficiency was 2.8 months. Detection of protein $S$ deficiency after the acute phase of the thrombosis may suggest a true deficiency of protein $S$ among our sample of patients. Finally, the most frequently recorded female-specific risk factors were puerperium $(\mathrm{n}=15,29.4 \%)$ and Oral Contraceptive Pills $(\mathrm{n}=8,15.7 \%)$.

Data concerning the radiological features of the included patients are displayed in Table 4. The most frequently utilised modalities were CT scan and MRI. The majority of the patients had non-haemorrhagic parenchymal lesions $(n=24,47 \%)$. The most frequently involved sinus was the transverse sinus $(n=39,76.5 \%)$ and more than half of the patients had more than one sinus involved.

Most of the patients with CVT received warfarin $(\mathrm{n}=39,76.5 \%)$, and 14 patients $(27.5 \%)$ were treated with low-molecular-weight heparin (LMWH). The number of patients who received dual treatment with both warfarin and LMWH was 13 (25.5\%), while 11 patients $(21.6 \%)$ were treated with anticoagulants other than warfarin and LMWH.

Discussion. This study was a retrospective review of the medical records of 51 patients diagnosed with CVT in Jazan region between 2010 and 2019. The majority of the patients were females and the most frequently recorded chronic disease among this sample of patients was hypertension. Most of the patients suffered headache and seizure, but the majority of the patients had no limb weaknesses, numbness, loss of sensation or palsy. The most commonly recorded risk factor was protein $S$ deficiency and the most frequently recorded femalespecific risk factor was puerperium. The majority of the patients had non-haemorrhagic parenchymal lesions.
The most frequently recorded acute complications were venous infraction and haemorrhage, while the most common chronic complication was epilepsy. By using warfarin and LMWH as treatment options, the majority of the patients had complete recovery and only one mortality was recorded.

The findings of the current investigation can be compared to other similar studies conducted in Saudi Arabia. Table 5 summarises the comparison between the current study and other similar studies, such as the Khobar study, ${ }^{13}$ Jeddah and Al-Baha ${ }^{7}$ and Riyadh ${ }^{14}$ in Saudi Arabia. The number of medical records included varied between 111 and 22, and the majority of the patients in all the studies were females. The average age of the patients varied between 29 and 38 years. The most common symptoms recorded in all the studies was headache. However, protein S deficiency was the most frequently reported risk factor in the current investigation, while other factors relating to OCP and pregnancy were more common in other studies. Similarly, none of the other studies included in Table 5 reported anaemia as a risk factor, which may indicate an association between anaemia and CVT in Jazan region. The involvement of sinuses in CVT was similar in all the studies. Finally, unlike our study, haemorrhagic lesion was recorded to be the most common type of parenchymal lesion.

In addition to the high incidence of CVT among females reported in the Saudi studies, this pattern is also observed in other international studies. This indicates the high association between pregnancy-related factors and incidence of the disease. ${ }^{15-17}$ However, anaemia was indicated in our investigation as one of risk factors that was frequently reported among patients in our cohort. This is similar to what was observed in a Tunisian study involving 160 patients with CVT, where it was noted that anaemia was one of the main risk factors of the disease. ${ }^{18}$ It is possible to argue that detecting anaemia as a risk factor of CVT in Jazan region is related to the higher prevalence of hemoglobinopathies in the south of Saudi Arabia. ${ }^{19}$

The majority of the cases identified in our investigation recovered, with no acute or chronic complications. This is similar to the findings of similar studies conducted in Saudi Arabia, where the recovery rate reached $66 \%{ }^{7}$ and $82 \% .{ }^{14}$ This is also similar to the recovery rate detected in our study, which reached $66 \%$ of the identified cases.

Only one case of mortality was detected in the current investigation, suggesting a low mortality rate among patients diagnosed with CVT. This notion is supported by similar low mortality rates detected in other studies. ${ }^{7,15,20,21}$ However, the mortality due to CVT 
has been reported to increase among older populations suffering from the disease and among those who are suffering from other comorbidities, such as sepsis and malignancy. ${ }^{20}$

This study has several strengths and weaknesses. The investigation was able to identify patients diagnosed with CVT in Jazan region, where the number of patients was relatively high in comparison with other similar studies conducted in Saudi Arabia. Additionally, this investigation was able to identify the demographic and clinical characteristics of CVT patients and identify the frequency of risk factors pertaining to a population that has not been studied before. The weaknesses of this investigation are related to the retrospective nature of this study and its dependence on the medical records of patients, many of which were excluded due to being incomplete.

In conclusion, The demographic and clinical presentation of CVT in Jazan region is similar to other local and international studies. The frequency among female patients was higher in our cohort of patients in a similar pattern to other similar studies. However, unlike other similar studies conducted in Saudi Arabia, anaemia was recorded as a frequent risk factor for the disease.

Recommendation for future research. The findings of this investigation suggest a need to conducted further research to assess the possible association between prevalence of anaemia in Jazan region and the incidence of CVT.

Acknowledgment. The authors acknowledge the valuable contribution of Dr. Ali Kamli, consultant of neuroradiology, in verifying clarity and correctness of the radiological features reported in this study. Additionally, the Medical Records Department at King Fahad Central Hospital in Jazan is highly appreciated for facilitating data collection. We would like to thank Student Proofreading.co.uk (Wales) Limited for English language editing.

\section{References}

1. Stam J. Thrombosis of the Cerebral Veins and Sinuses. N Engl J Med 2005; 352(17): 1791-1798.

2. Danwang C, Mazou TN, Tochie JN, Tankeu R, Bigna JJ. Global epidemiology and patterns of cerebral venous thrombosis: a systematic review and meta-analysis protocol. BMJ open 2018; 8: e019939.

3. Field T, Hill M. Cerebral Venous Thrombosis We Should Ask the Right Questions to Get Better Answers Thalia. Stroke 2019; 50: 1598-1604.

4. Devasagayam S, Wyatt B, Leyden J, Kleinig T. Cerebral Venous Sinus Thrombosis Incidence Is Higher Than Previously Thought. Stroke 2016; 47: 2180-2182.

5. Janghorbani M, Zare M, Saadatnia M, Sa M, Mojarrad M. Cerebral vein and dural sinus thrombosis in adults in Isfahan, Iran: frequency and seasonal variation. Acta Neurol Scand 2008; 117: 117-121.
6. Daif A, Awada A, Al-Rajeh S, Abduljabbar M, al Tahan A, Obeid T, et al. Cerebral Venous Thrombosis in Adults. Stroke 1995; 26: 1193-1195.

7. Algahtani HA, Abdu AP, Shami AM, Hassan AE, Madkour MA, Al-Ghamdi SM, et al. Cerebral venous sinus thrombosis in Saudi Arabia. Neurosciences (Riyadh) 2011; 16: 329-334.

8. Silvis SM, Sousa DAD, Ferro JM, Coutinho JM. Cerebral Venous Thrombosis. Nature 2017; 13: 555-565.

9. Zuurbier SM, Coutinho JM. Cerebral Venous Thrombosis. In: Islam M, editor. Thrombosis and Embolism: from Research to Clinical Practice. Advances in Experimental Medicine and Biology. Cham (CH): Springer; 2016.

10. Algahtani $\mathrm{H}$, Aldarmahi A. Cerebral venous sinus thrombosis. Neurosciences 2014; 19: 11-16.

11. Siddiqui FM, Kamal AK. Complications associated with cerebral venous thrombosis. J Pak Med Assoc 2006; 56: 547-551.

12. Haghighi AB, Edgell RC, Cruz-Flores S, Feen E, Piriyawat P, Vora N, et al. Mortality of cerebral venous-sinus thrombosis in a large national sample. Stroke 2012; 43: 262-264.

13. Shahid R, Zafar A, Nazish S, Alsulaiman A, Alabdali M, Aljaafari D, et al. Etiologic and Clinical Features of Cerebral Venous Sinus Thrombosis in Saudi Arabia. J Neurosci Rural Pract 2019; 10: 278-282.

14. Kajtazi NI, Zimmerman VA, Arulneyam JC, Al-Shami SY, Al-Senani FM. Cerebral venous thrombosis in Saudi Arabia. Clinical variables, response to treatment, and outcome. Neurosciences (Riyadh) 2009; 14: 349-354.

15. Gunes HN, Cokal BG, Guler SK, Yoldas TK, Malkan UY, Demircan CS, et al. Clinical associations, biological risk factors and outcomes of cerebral venous sinus thrombosis. J Int Med Res 2016; 44: 1454-1461.

16. Pan L, Ding J, Ya J, Zhou D, Hu Y, Fan C, et al. Risk factors and predictors of outcomes in 243 Chinese patients with cerebral venous sinus thrombosis: A retrospective analysis. Clin Neurol Neurosurg 2019; 183: 105384.

17. Lee DJ, Ahmadpour A, Binyamin T, Dahlin BC, Shahlaie K, Waldau B. Management and outcome of spontaneous Cerebral venous sinus thrombosis in a 5-year consecutive singleinstitution cohort. J Neurointerv Surg 2017; 9: 34-38.

18. Sassi SB, Touati N, Baccouche H, Drissi C, Romdhane NB, Hentati F. Cerebral Venous Thrombosis: A Tunisian Monocenter Study on 160 Patients. Clin Appl Thromb Hemost 2017; 23: 1005-1009.

19. Alsaeed ES, Farhat GN, Assiri AM, Memish Z, Ahmed EM, Saeedi MY, et al. Distribution of hemoglobinopathy disorders in Saudi Arabia based on data from the premarital screening and genetic counseling program, 2011-2015. J Epidemiol Glob Health 2018; 7: S41-S47.

20. Nasr DM, Brinjikji W, Cloft HJ, Saposnik G, Rabinstein AA. Mortality in cerebral venous thrombosis: Results from the national inpatient sample database. Cerebrovasc Dis 2013; 35: 40-44.

21. Coutinho JM, Zuurbier SM, Stam J. Declining mortality in cerebral venous thrombosis: A systematic review. Stroke 2014; 45: 1338-1341. 